\title{
RELATIONS BETWEEN GRACE-DERIVED WATER STORAGE CHANGE WITH PRECIPITATION AND TEMPERATURE OVER KAIDU RIVER BASIN, CHINA
}

\author{
J. Huang ${ }^{\text {a, b, } * \text {, Q. Zhou }}{ }^{\text {a, b }}$ \\ ${ }^{\text {a }}$ Shenzhen Institutes of Advanced Technology, Chinese Academy of Science, 518055 Shenzhen, China \\ ${ }^{\mathrm{b}}$ Department of Geography and Centre for Geo-computation Studies, Hong Kong Baptist University, Hong Kong, China - \\ jrhuang@life.hkbu.edu.hk \\ Commission VIII, WG VIII/4
}

KEY WORDS: GRACE, Terrestrial Water Storage, Precipitation, Temperature, Kaidu River Basin

\begin{abstract}
:
Water is essential for human survival and well-being, and important to virtually all sectors of the economy. In the aridzone of China's west, water resource is the controlling factor on the distribution of human settlements. Water cycle variation is sensitive to temperature and precipitation, which are influenced by human activity and climate change. Satellite observations of Earth's timevariable gravity field from the Gravity Recovery and Climate Experiment (GRACE) mission, which enable direct measurement of changes of total terrestrial water storage, could be useful to aid this modelling. In this pilot study, TWS change from 2002 to 2013 obtained from GRACE satellite mission over the Kaidu River Basin in Xinjiang, China is presented. Precipitation and temperature data from in-situ station and National Satellite Meteorological Centre of China (NSMC) are analysed to examine whether there is a statistically significant correlation between them.
\end{abstract}

\section{INTRODUCTION}

The Xinjiang Uygur Autonomous Region, situated in northwest China, is in the hinterland of the Eurasian continent and stretches from $35^{\circ} \mathrm{N}$ to $50^{\circ} \mathrm{N}$ and $73^{\circ} \mathrm{E}$ to $95^{\circ} \mathrm{E}$ (Figure 1). It comprises approximately 1.66 million $\mathrm{km}^{2}$ and accounts for $16.7 \%$ of total land area of China. The region is remote from oceans and exhibits typical mid-altitude continental climate of the northern hemisphere (Liu et al. 2010), characterized by very high potential evaporation and low precipitation. Water resources in the study area come from high mountain glaciers, seasonal snowmelt, middle mountain precipitation, and water emanating from fractured bedrock in the lower mountains (Chen et al. 2014a). Precipitation is scarce and not regarded a primary source of water replenishment.

In recent decades, increasing precipitation and runoff were found in some mountainous areas. Projections by existing regional climate models confirmed the transformation into a warm-wet climate, but the rate and magnitude of the transformation are yet subject to further investigation (Chen et al. 2014b). Water cycle variation is sensitive to both human activity and climate change. However, this measurement is limited by the available data in arid endorheic river basins is typically limited in terms of extent and quality. Satellite observations of Earth's time-variable gravity field from the Gravity Recovery and Climate Experiment (GRACE) mission, which enable direct measurement of changes of total terrestrial water storage, could be useful to aid this modelling.

\section{METHODOLOGY}

Data from GRACE satellites, which measure the variation in the gravity field, is used to estimate the spatio-temporal TWSC during the study period (2002-2013). The monthly GRACE gravity field consists of a set of spherical harmonic coefficients.
These fields can be then spatially averaged to generate time series of total water storage anomalies (Song et al. 2015). After removal of the temporal mean, the GRACE field is filtered using the $300 \mathrm{~km}$ wide Gaussian filter method and finally converted to mass in units of equivalent water thickness. Subsequently, these processed spherical harmonic coefficients were transformed into gridded data. The mass variations were then converted to TWSC in units of equivalent water height (EWH). In this study, we will use the latest GRACE-Tellus Release-05 gridded Level-3 data of monthly surface mass changes, provided by the Centre for Space Research (CSR) at the University of Texas (http://grace.jpl.nasa.gov/data/), which is supported by the NASA MEaSUREs Program. The global TWS data are updated monthly since 2002 and available with $1 \times 1$ degree spatial resolution with the measurement of equivalent water thickness in centimetre (Wahr et al. 2004). Atmospheric water storage changes, which have been removed from the signal during the TWS retrieval process, are not considered in this proposed study.

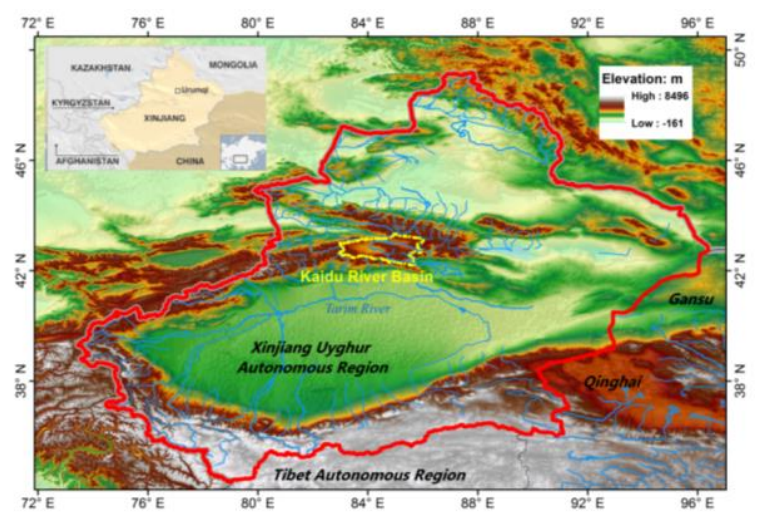

Figure 1. Study area

\footnotetext{
* Corresponding author
} 
Daily or monthly weather data (e.g. temperature, rainfall, and wind speed) are acquired from weather stations across the region. In ungauged basins, the rainfall gauge data is supplemented by inversion result from meteorological satellite imageries, such as FY_2C provided by the National Satellite Meteorological Centre of China (NSMC). In addition, base maps of ground features (river, basin boundary, administrative boundary, etc), a digital elevation model (DEM) with grid resolution $30 \times 30 \mathrm{~m}$ are available.

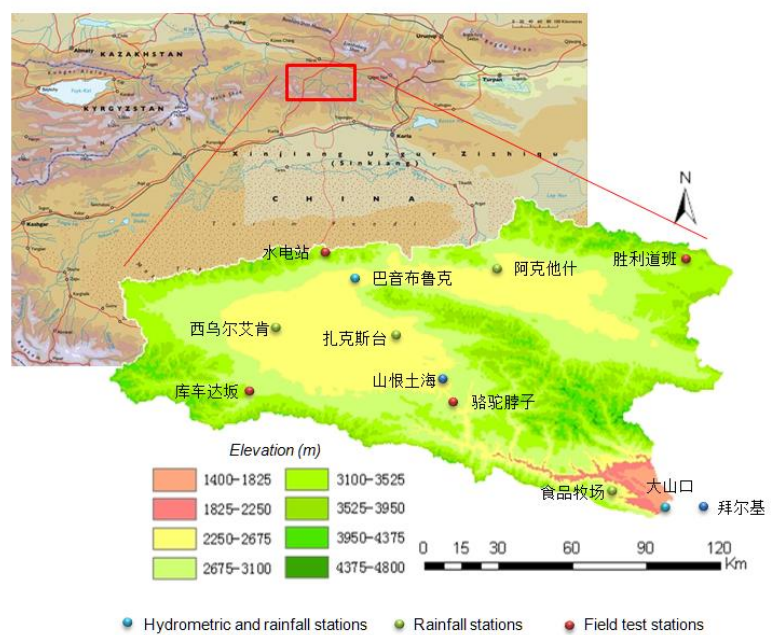

Figure 2. The location of preliminary field test stations (red) and controlling hydrometric/rainfall stations (blue) and rainfall stations (green).

For our further study, several experimental field data logging stations have been established in the study sites (Kaidu River Basin) by previous research projects collaborated with Xinjiang Institute of Ecology and Geography, China Academy of Sciences (Figure 2). Some data has been collected and is under processing. Runoff gauges have been installed in the main tributaries of each drainage basin. These hydro-climatic parameters represent the temporal flow patterns along the upper- and mid-reaches and the corresponding climatic variation.

\section{PRELIMINARY RESULT AND DISCUSSION}

\subsection{TWS Change and the Relations with Rainfall and Temperature}

According to the GRACE-derived data, significant decrease of terrestrial water storage in study site (Kaidu River basin, east Tianshan region) can be observed. There has been, however, an obvious increase of water storage in other area of Xinjiang, which is partly due to the degradation and melting of permafrost (Figure 3).

In Kaidu River Basin, a typical watershed in the Tianshan Mountain with a drainage area of $18,634 \mathrm{~km}^{2}$, TWS change data and weather observation record in Bayanbulak station are analysed. The monthly changes of GRACE TWS are tightly associated with the monthly change of temperature, and moderately related to the monthly change of precipitation, as precipitation is scarce and not regarded a primary source of water replenishment (Figure 4). In terms of seasonal variation, there is a significant correlation relation between of TWS change and rainfall amount between 2002 and 2007, with a certain lag time. The maximum monthly increase of TWS occurs in March to May, while the maximum monthly rainfall occurs in June to August.

These trends suggest that the TWS decrease was likely caused by a regional increase in precipitation and temperature, which have led to increase out of basin runoff (upstream to downstream of Kaidu River Basin). The data also displays a decrease trend of TWS in the study area since 2007, whereas the rainfall variation has been limited. The anthropogenic alteration, such as groundwater depletion for agricultural usage, might be the contributing factor.

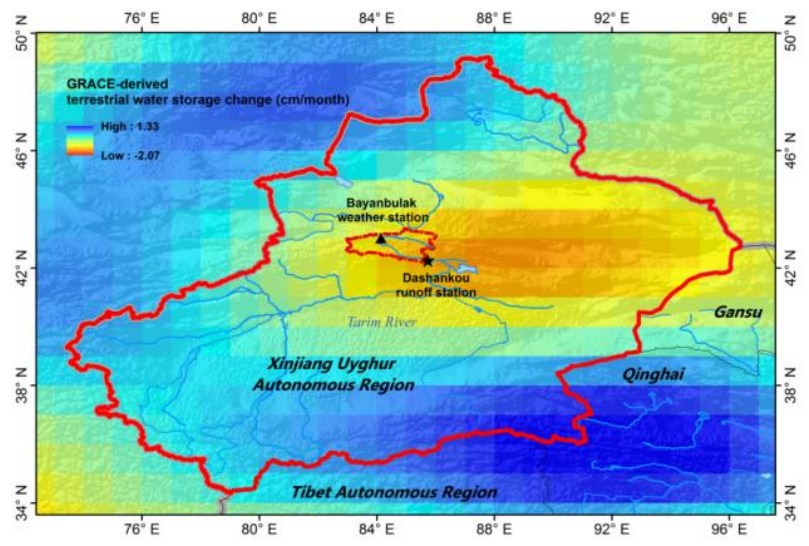

Figure 3. Changing rates of terrestrial water storage ( $\mathrm{cm} / \mathrm{month}$ ) in Xinjiang from 2003 to 2013

\subsection{Strategy for Estimating Groundwater Change from GRACE}

Groundwater is one primary source of water in the region. Available result suggests that unsustainable consumption of groundwater, for irrigation and other anthropogenic uses, poses a significant challenge in regional sustainable development. Nevertheless, measurement of the groundwater depletion is

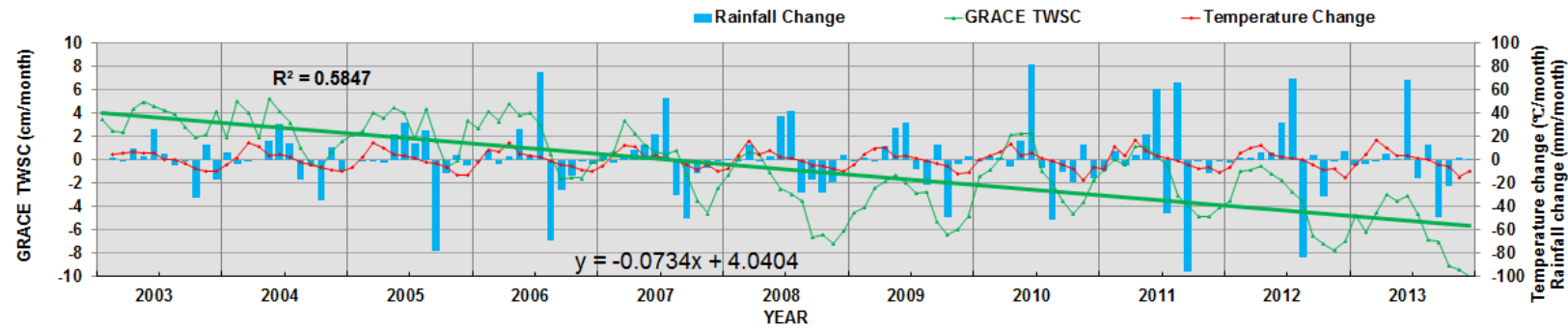

Figure 4. Month to month changes of terrestrial water storage, rainfall and temperature in Kaidu River Basin from 2003 to 2013 
limited, as available data in arid endorheic river basins is typically limited in terms of extent and quality.

Groundwater storage variations can be isolated from GRACEderived TWS change, with auxiliary information of the other components in the water cycle (snow water equivalent storage (SWES), surface water reservoir storage (RESS), soil moisture storage (SMS)), from in situ observations, land-surface models or remote sensing change detection. Therefore, changes in groundwater storage (GWS) can be calculated as a residual from the disaggregation equation:

$$
\text { GWS }=\Delta \mathrm{TWS}-\Delta \mathrm{SWES}-\Delta \mathrm{RESS}-\Delta \mathrm{SMS}
$$

\section{CONCLUSION}

This pilot study primarily examines the feasibility of the latest GRACE-Tellus RL-05 gridded Level-3 data of monthly surface mass changes for hydrological study in Xinjiang. It can be concluded that there is certain correlation relationship between TWS change in our study area and temperature and rainfall. Further investigation is extended to study the lag effect of rainfall and TWS change, and examine the efficiency of GRACE for quantifying the spatial-temporal changes of individual hydrological components (e.g groundwater) in a greater spatial coverage. Through this study a better understanding about the regional water cycle in the aridzone is anticipated.

\section{ACKNOWLEDGEMENTS}

This study is supported by "International Science \& Technology Cooperation Program of China (2010DFA92720-24)", Natural Science Foundation of China (NSFC) General Research Grant (41471340), Research Grants Council (RGC) of Hong Kong General Research Fund (GRF) (HKBU 203913) and Hong Kong Baptist University Faculty Research Grant (FRG1/1415/073).

\section{REFERENCES}

Chen, Y., Li, B., Xu, C., 2014a. Climate System in Northwest China. In: Chen, Y. (Ed.), Water Resources Research in Northwest China. Springer Netherlands, Dordrecht, pp. 51-108.

Chen, Y., Li, B., Chen, Z., Fan, Y. 2014b. Hydrologic System in Northwest China. In: Chen, Y. (Ed.), Water Resources Research in Northwest China. Springer Netherlands, Dordrecht, pp. 109-144.

Liu, C., Chen, Y., Xu, Z., 2010. Eco-hydrology and sustainable development in the arid regions of China. Hydrological Processes, 24(2), pp. 127-128.

Song, C., Ke, L., Huang, B., Richards, K. S., 2015. Can mountain glacier melting explains the GRACE-observed mass loss in the southeast Tibetan Plateau: From a climate perspective? Global and Planetary Change, 124, pp. 1-9. doi:10.1016/j.gloplacha.2014.11.001

Wahr, J., Swenson, S., Zlotnicki, V., Velicogna, I., 2004. Timevariable gravity from GRACE: first results. Geophysical Research Letters, 31, L11501. 